\title{
Artelogie
}

arte ogie

Recherche sur les arts, le patrimoine et la littérature de l'Amérique latine

1 | 2011

Brésil, questions sur le modernisme

\section{Permanência da forma: uma conversa entre os ensaios de Michel de Montaigne e Mário de Andrade}

Ricardo Gaiotto de Moraes

\section{(2) OpenEdition}

Edição electrónica

URL: https://journals.openedition.org/artelogie/8391

DOI: 10.4000/artelogie.8391

ISSN: 2115-6395

Editora

Association ESCAL

Refêrencia eletrónica

Ricardo Gaiotto de Moraes, «Permanência da forma: uma conversa entre os ensaios de Michel de Montaigne e Mário de Andrade», Artelogie [Online], 1 | 2011, posto online no dia 01 março 2011, consultado o 07 janeiro 2022. URL: http://journals.openedition.org/artelogie/8391 ; DOI: https:// doi.org/10.4000/artelogie.8391

Este documento foi criado de forma automática no dia 7 janeiro 2022.

Association ESCAL 


\title{
Permanência da forma: uma conversa entre os ensaios de Michel de Montaigne e Mário de Andrade
}

\author{
Ricardo Gaiotto de Moraes
}

\section{Desdobramentos do eu, desdobramentos do gênero}

1 Refletir por escrito sobre a forma do ensaio é tarefa ingrata. Já no início da empreitada, o autor, mesmo pressentindo o canto da sereia, fica também tentado a apoderar-se da forma ensaística que vai lhe fugindo a cada tentativa de análise mais sistemática. Até mesmo o domínio sobre o registro da linguagem, antes quase natural, vai se esgarçando à medida que o texto se desenrola. $O$ ensaio parece ser forma leve demais para comportar o jargão acadêmico e muitas páginas debruçadas sobre o mesmo objeto.

Os grandes ensaístas também olharam com desconfiança para essa forma localizada na fronteira entre intuição e análise. Georg Lukács, em 1910, inicia carta a Leo Popper sobre a "essência da forma do ensaio", duvidando da possibilidade de conseguir constituir um livro a partir da reunião de vários ensaios: "tenho diante de mim os ensaios destinados a este livro, e me pergunto: devem-se publicar trabalhos dessa ordem, pode surgir deles uma nova unidade, um livro?"1

3 A dúvida de Lukács aponta para questões comuns nos escritos daqueles que se debruçaram sobre o estudo do ensaio, quais sejam, o caráter fragmentário do texto, cujo desenvolvimento guina de um tema a outro, às vezes movido por um impulso de difícil compreensão, e a transitoriedade manifesta das idéias elucubradas que teriam eficiência como artigo circunstancial, mas não como volume livresco. Percepção semelhante teve Mário de Andrade ao comentar - em carta enviada, em 1942, a Manuel Bandeira - sua angústia para selecionar os artigos de crítica literária que fariam parte dos volumes Aspectos da Literatura Brasileira e O Empalhador de Passarinho. A necessidade de estabelecer em livro artigos cuja finalidade era a crítica circunstancial dos jornais 
deixaria o autor em um estado de "tristeza" devido à "sensação de leviandade" por não poder reescrever os artigos, pensando na transposição para o livro².

O sentimento de culpa do escritor, manifestado na palavra "leviandade", e o impulso de reescrever os "artigos", levando em conta a necessária unidade de um livro, sugerem, por um lado, cuidado com a forma: o caráter fragmentário e leviano do ensaio seria mais apropriado à efêmera duração de um número de jornal; já à publicação em livro seria necessário imprimir maior seriedade nos juízos e resgatar a unidade perdida no ensaio. Por outro lado, a inquietação, quase culpada, está ligada à máscara assumida pelo autor em cada gênero. Assim, a "leviandade" do ensaio alude também à exposição do eu, tornando a máscara mais translúcida.

Georg Luckás e Mário de Andrade, escritores de domínios tão distintos, ao refletirem sobre a forma do ensaio, dialogam sobre o gênero, cujo iniciador foi Montaigne. Este, aliás, é mencionado em textos dos dois escritores do século XX. Mário de Andrade aconselha a uma de suas alunas a leitura de poucos filósofos, destacando as leituras que fez de Montaigne, Platão e Aristóteles ${ }^{3}$. Além disso, consta na biblioteca do autor brasileiro os Essais de Montaigne: publiés d'aprés l'édition de 1588 avec les variantes de 1595. Lukács, por sua vez, na carta a Leo Popper situa Montaigne entre os grandes ensaístas. A aproximação livre entre as preocupações com a escrita ensaística de Lukács e Mário de Andrade parece revelar características comuns que se completam com a leitura da advertência que Montaigne, no século XVI, faz a seu leitor, na qual afirma que os Ensaios seriam uma "pintura" de si, na qual se mostraria de "maneira simples, natural e habitual, sem apuro e artifício"4. Assim, a matéria última do livro seria o próprio escritor.

assumir o ensaio como uma "pintura" de si, Montaigne explicita que os juízos elaborados em seus escritos partem de sua intuição e, de certa forma, são constituintes de sua personalidade. Assim, se a matéria e o juízo são assumidamente humanos e, portanto, mutáveis, as contradições e o caráter transitório são características integrantes do gênero posto em circulação pelo autor. Esse tipo de consideração é constante, em "Do arrependimento", por exemplo, quando o escritor francês afirma não conseguir fixar o objeto do qual trata, porque o objeto é ele próprio, ser mutável. Nesse caso, em seu registro dos acontecimentos poderia se contradizer, sem contradizer a verdade - pelo menos aquela concernente ao momento da escrita.

7 Essa busca fragmentária de si, verbalizada nos ensaios, parece ser influenciada pelo contato de Montaigne com certos gêneros da Antiguidade. Michel Foucault, ao estudar, na filosofia antiga, o conceito de askêsi, define que esta "deve ser compreendida como um treino de si por si mesmo"s. Esse exercício, para Sêneca, deveria passar obrigatoriamente pela escrita. Foucault flagra esse tipo de escrita em dois gêneros da Antiguidade: os hupomnênata, caderno fragmentário de anotações das leituras e das experiências, e a correspondência, que muitas vezes figurava quase como um "relato epistolar de si mesmo". Os Ensaios de Montaigne estão justamente no limite entre os hupomnênata e a correspondência, pois a busca do eu se constitui a partir da confrontação com o outro. Marc Fumaroli, nesse sentido, aproxima os monólogos dos Ensaios, de Montaigne, a um constante diálogo, no qual deveria existir a confrontação com o outro, tratar-se-ia "pura e simplesmente de se comparar com outrem face a face, a fim de tornar sua medida exata e quebrar seus próprios ídolos."

8 Esse lugar intermediário do ensaio entre a escrita de si e a relação com o outro, que constitui a necessidade de o autor assumir uma máscara mais translúcida, é também constante nos ensaios e na correspondência literária de Mário de Andrade. Essa posição 
é conscientemente assumida, por exemplo, em "Começo de Crítica", artigo de abertura de sua coluna de crítica literária, publicado entre 1939 e 1940 no jornal carioca Diário de Notícias. Nesse texto, Mário de Andrade reconhece que sua obra ficcional fora ditada por certo utilitarismo. $O$ tom de confissão e de reorganização do eu aparece na medida em que, na continuidade do texto, afirma sentir, por um lado, alguma satisfação por sua obra e, por outro, ressentir-se um pouco pela recepção de Macunaíma, que fora lido não como a sátira inflamada que era, mas como um sussurro de imoralidade. Ao mesmo tempo em que responde a certa crítica sobre Macunaíma, prevendo o confronto com o leitor, também assinala aquilo que será uma das linhas mestras da recepção posterior de sua própria obra, ou seja, a noção de que esta fora marcada pelo sacrifício. Ou seja, o poeta teria renunciado voluntariamente elaborar uma obra esteticamente mais bem delineada pela necessidade de engajamento tanto nas propostas de experimentação estética, cujas matrizes foram as vanguardas europeias, quanto nas propostas nacionalistas de busca de uma expressão pautada na pesquisa do que entendia como cultura brasileira.

O tom quase melancólico, assumido no ensaio, para descrever as escolhas artísticas dá lugar, na correspondência, a um discurso mais enérgico, mais direto e também mais didático. Em carta a Carlos Drummond de Andrade, o autor de Macunaíma afirma que sua arte seria, de início, como uma pregação, depois, como uma demonstração". A clareza que marca o estilo mais direto torna-se explícita no momento no qual afirma que a confissão do pragmatismo de sua obra seria doloroso "se não fosse um homem que antes de mais nada vive e ama e se devotou inteiramente à vida e aos amores dele". Mesmo assim, acaba afirmando que a franqueza dependeria, obviamente, da identidade do destinatário. A confissão permeia, portanto, ensaio e carta, o que muda é o tom de franqueza, cujos limites se estabelecem a partir da escolha do destinatário. Na continuidade do artigo "Começo de Crítica", Mário de Andrade confere à crítica literária status de obra de arte. Assim, enquanto aquela seria uma "invenção sobre um determinado fenômeno artístico", esta "uma invenção sobre um determinado fenômeno natural". Assim, a crítica literária elaboraria uma "nova síntese puramente irreal" capaz de revelar o elemento que serviria "de base à criação". A crítica e, por extensão, o ensaio literário seriam considerados também, pelo poeta modernista, como lugar de verdades transitórias ("nova síntese") determinadas pelas contingências do eu. Essa transitoriedade daria à crítica valor de obra de arte, pois seria também invenção, originária da intuição. Ao ensaísta seria permitido, portanto, a "leviandade", como já apontado no comentário que faz sobre os artigos circunstanciais a serem publicados como livro.

10 Adorno, num texto de 1910, O ensaio como forma, também concedera ao ensaísta a possibilidade de afirmar sem rigidez de método. 0 autor afirma que o ensaio, "ao se abster de qualquer redução a um princípio e ao acentuar, em seu caráter fragmentário, o parcial diante do total", seria uma das únicas formas em que se questiona o "direito incondicional do método" [...]. O ensaio questionaria, portanto, a ideia disseminada por Platão de que "o mutável e o efêmero não seriam dignos de filosofia". Esse gênero duvidaria, portanto, da idéia de que a realidade pode ser reduzida a uma totalidade regida pelo método. Dessa maneira, o objetivo do ensaio não seria "procurar o eterno no transitório, nem destilá-lo a partir deste, mas sim eternizar o transitório." "

11 No texto de Adorno, pode-se perceber ainda a defesa do ensaio como única forma que admite o erro, pois seria espaço do exercício. E se, como afirma, o ensaio flagra o 
sujeito, o pensador faz de "si mesmo o palco da experiência intelectual, sem desemaranhá-la" da natureza de seu objeto: "[...] o que determina o ensaio é a unidade de seu objeto, junto com $a$ unidade de teoria e experiência que o objeto acolhe" ${ }^{10}$. No entanto, discorda da idéia de que o ensaio teria natureza próxima à obra de arte, contrariando, assim, o que afirmara Lukács e Mário de Andrade. Para Adorno, o ensaio apresentaria em comum com a arte apenas o esforço de se referir a um objeto - a obra de arte ou, nos termos que estamos desenvolvendo aqui, o próprio homem - sem usar a mesma expressão que ele. Não seria, por isso, obra de arte, mas estaria mais próximo da teoria por elaborar também um conceito. Essa faceta tornaria o ensaio uma espécie de "heresia", pois, mesmo partindo da mesma forma de explanação da teoria, possuiria uma existência cuja marca mais característica é o questionamento da ideologia.

\section{Conversa ensaiada}

É necessário agora acompanhar os movimentos de Montaigne e Mário de Andrade no desenrolar dos ensaios para perceber se aquilo que afirmam sobre si mesmos está presente em seus escritos.

Montaigne inicia o ensaio intitulado "Do jovem Catão" como se escrevesse uma conversa sobre costumes: "Não faço o erro comum de julgar um outro de acordo com o que sou"11. O respeito à alteridade o levaria a reconhecer e admirar a virtude do outro, mesmo que a sua estivesse degenerada. Não é porque em seu mundo, no mais das vezes, a virtude era impulsionada por outros aspectos como o gosto pedante do aplauso público, que não se devesse reconhecer que esse bem não estava apenas nos "livros escolares". Assim, acreditava ser negativo o movimento de certos escritores que reinterpretavam as grandes ações e os grandes nomes do passado, rebaixando-os para justificar a depravação dos costumes contemporâneos. Sendo assim, Montaigne via como seu papel fazer esforço contrário ao daqueles escritores, elevando os homens do passado, pois seria tarefa das pessoas de bem "pintar a virtude o mais belamente possivel"12. Nesse primeiro movimento, há uma justificativa para o "homem de bem" continuar o ensaio apresentando o personagem a ser pintado, ou seja, Catão. Apesar de ter conferido um caráter universal à virtude, incorre aqui num paradoxo, pois descreverá as atitudes virtuosas de seu personagem, impulsionado por uma necessidade moralista ligada ao mundo de Montaigne e não apenas por considerar que "esse personagem foi realmente um modelo que a natureza escolheu para mostrar até onde podem chegar a virtude e a firmeza humanas." ${ }^{\prime 13}$

continuidade do texto, Montaigne muda a direção manifesta do ensaio, passa a apresentar a poesia de Ovídio, Lucano e Virgílio sobre Catão. No entanto, ao refletir sobre a natureza da poesia, chega à conclusão de que seria mais fácil fazê-la que a conhecer. Isso ocorreria porque, mesmo que fosse possível um julgamento rasteiro por preceitos e pela elaboração artística, "a boa, a excelente, a divina" poesia estaria "acima das regras e da razão" ${ }^{14}$. Nesse caso, ela não apenas seduziria o nosso julgamento, mas o arrebataria e devastaria.

Para definir esse arrebatamento, Montaigne usa a imagem de um imã platônico que, ao atrair uma agulha, imanta-a e a faz atrair outra. Depois de citar trechos de Ovídio e Lucano, termina o ensaio com um verso de Virgílio. Parece que o próprio Montaigne foi arrebatado pela forma poética e seu movimento foi definido pelo objeto que discutia. Além disso, há um entrelaçamento no desfecho entre os dois assuntos do ensaio: o 
anunciado explicitamente, a poesia sobre Catão, e o do substrato, a discussão da importância da virtude. Nesse caso, o caráter fragmentário do ensaio pode ser verificado não só na cadência dos argumentos, mas também, como ensina Adorno, na própria insegurança causada pelo caráter pessoal e por isso transitório do ensaio.

Tanto o arrebatamento do escritor pelo rastro tênue das impressões, quanto a estratégia do despistamento, para esboçar o assunto anunciado e o do substrato do ensaio, são técnicas trilhadas também por Mário de Andrade no interior de seus escritos. O autor de Macunaíma é mestre na arte de, com um tom de conversa ou de piada, minuciosamente desvendar detalhes de um poema capazes de nortear vários caminhos interpretativos pelos quais sua escrita vai trilhando e arrebatando também o leitor. A aproximação com o outro se dá por uma trama de impressões, cujo tom oral característica que Davi Arrigucci Jr ${ }^{15}$ afirma ser uma das heranças da crítica modernista - familiariza o leitor e lhe outorga também o direito de enlevo.

No ensaio Vários Poetas, por exemplo, depois de citar um trecho de um livro de poemas de Freitas Pacheco, Mário de Andrade conclui: "Diabo ! Diabo !... o poema não chega a ser bom, tem coisas desengonçadas, mas este anseio de definição sem pensamento científico é de muito boa qualidade lírica." ${ }^{16}$ Quebra, então, as boas expectativas do leitor, afirmando que, na verdade, aquele poema se tratava do índice do livro ${ }^{17}$. A piada obviamente serve de pretexto para Mário de Andrade continuar seus esforços em criticar os poetas que não prezavam o cuidado com a forma.

19 Assim, não é apenas pelo caráter sinuoso da linha argumentativa que Mário se aproxima de Montaigne. Retomando o ensaio sobre Catão, se para Montaigne o importante era destacar a virtude de Catão, para Mário de Andrade, o crivo é a identificação, na obra literária, do "essencial da arte", que pode ser entendido como a busca do desenvolvimento da técnica do artista. Assim, no decorrer da coluna "Vida Literária”, receberão juízo positivo os artistas que, para o crítico, tenham almejado, como Machado de Assis ${ }^{18}$, desenvolver mais sua técnica que as "modas" literárias vigentes.

Além da permanência da forma, a comparação entre os escritos de Montaigne e Mário de Andrade poderia se dar por meio da análise do lugar ocupado pelos ensaios. Erich Auerbach afirma, em "O escritor Montaigne", que os ensaios de Montaigne não demonstrariam especialização ou aprofundamento em qualquer assunto, não possuiriam sistema ou método de um filósofo nem apresentariam linguagem simbólica própria de um poeta. $\mathrm{O}$ escritor francês teria criado, portanto, "uma nova categoria social: o homme de lettres ou écrivain", ou seja, o leigo que ocuparia a profissão de escritor"19. A forma intermediária do ensaio faria com que Montaigne se dirigisse a um público ainda em formação, pois "não escrevia nem para a corte nem para o povo, nem para os católicos nem para os protestantes, nem para os humanistas, nem para alguma outra coletividade". Para Auerbach, "o público dos Ensaios de Montaigne não existia, e ele não podia supor que existisse", escrevia, assim, para a categoria "público culto"

21 O "público culto" almejado por Montaigne seria consolidado apenas no séculos XIX com a burguesia e o jornal, espaço adequado para o respeitado "homem de letras" escrever seus ensaios, cujas preocupações passariam paulatinamente a englobar as necessidades da indústria cultural. A participação mais efetiva de Mário de Andrade nos jornais estaria localizada, por sua vez, justamente no momento em que o "homem de letras" cai em descrédito, sendo substituído paulatinamente pelo crítico acadêmico. 
Assim, enquanto os ensaios de Michel de Montaigne ocupam o limiar do período em que se formará um novo público, burguês, que se deleitará com as impressões dos homens de letras, os escritos de Mário de Andrade prenunciam um momento em que a exigência da especialização cobrará do crítico, se não um método totalmente rigoroso, uma maior disciplina no encadeamento das impressões. Apesar do antagonismo quase irônico da contingência do contexto de cada escritor, as semelhanças na maneira de abordar os temas e de definir as estratégias textuais nos revelam que a escrita de si, marca da forma ensaística, parece se universalizar na medida em que arrebata o escritor preocupado com a sinceridade da escrita, por mais que essa também consista em artifício.

\section{BIBLIOGRAFIA}

ADORNO, Theodor W. “O Ensaio como Forma”, in: Notas de Literatura I. Duas Cidades, São Paulo; Ed. 34, 2003.

ANDRADE, Mário de. A Lição do Amigo: cartas de Mário de Andrade a Carlos Drummond de Andrade. 1a. ed. J. Olympio, Rio de Janeiro, 1982.

ANDRADE, Mário de. Correspondência Mário de Andrade e Manuel Bandeira. Org. Marcos Antonio de Moraes. IEB/EDUSP, São Paulo, 2000.

ANDRADE, Mário de. O empalhador de passarinho. 2a. ed. Martins, São Paulo, 1955.

ANDRADE, Mário de. Vida Literária. Pesquisa, estabelecimento de texto, introdução e notas de Sonia Sachs.

HUCITEC/Edusp, São Paulo, 1993.ARRIGUCCI JR. Davi. “Movimentos de um leitor (Ensaios e imaginação crítica em Antonio Candido)", in: Outros achados e perdidos. Cia das Letras, São Paulo, 1999.AUERBACH, Eric. "O escritor Montaigne”, in: Ensaios de literatura occidental. Editora 34/ Duas Cidades, São Paulo, 2007.

FOUCAULT, M. Ética, Sexualidade, Política. Forense Universitária, Rio de Janeiro, 2004.FUMAROLI, Marc. "O Discurso do Método de Montaigne", in: A arte de persuadir. Martins Fontes, São Paulo, 2004.

LUCÁKS, Georg. 'Sobre a essência e a forma do ensaio: uma carta a Leo Popper'. Tradução de Mário Luiz Frungilo, in: Revista UFG, junho de 2008, ano X, $n^{\circ} 4$.

MONTAIGNE, Michel de. Os ensaios. Tradução de Rosemary Costhek Abílio, 3 volumes. Martins Fontes, São Paulo, 2006.

\section{NOTAS}

1. LUCÁKS, Georg. 'Sobre a essência e a forma do ensaio: uma carta a Leo Popper'. p. 104.

2. Texto original: "É estranho: principiei esta carta em estado simples mas agora me sinto num tal ou qual estado de tristeza... Deve ser essa sempre angústia de querer o melhor... Me fica assim como uma sensação 
de leviandade, de estar praticando um ato de leviandade dando estas coisas para a impressão em livros. Uma aspiração fatigada de refazer tudo isso, pensando 'livro' e não, pensando 'artigo' com que tudo isso foi escrito. Valerá à pena?... Valerá a pena, meu Deus !...” In: ANDRADE, Mário de. Correspondência Mário de Andrade e Manuel Bandeira. p. 662.

3. Texto original: "Filósofos mesmo, li poucos. Os sistemas não conseguiam me interessar, principalmente os modernos que me fatigavam pavorosamente. Só Montaigne que aliás é mais moralista que exatamente filósofo. Li Platão quase todo, talvez todo, e bastante Aristóteles". In: ANDRADE, Mário de. Mário de Andrade - Oneyda Alvarenga: cartas. p. 271.

4. Texto original: “[...] Quero que me vejam aqui [nos Ensaios] em minha maneira simples, natural e habitual, sem apuro e artifício: pois é a mim que pinto. [...] Nele meus defeitos serão lidos ao vivo, e minha maneira natural, tanto quanto o respeito público mo permitiu. [...] Assim, leitor, sou eu mesmo a matéria de meu livro: não é senso que empregues teu lazer em um assunto tão frívolo e tão vão." In: MONTAIGNE, Michel de. Os ensaios [vol. I], p. 4.

5. FOUCAULT, Michel. Ética, Sexualidade, Política. p. 147.

6. FUMAROLI, Marc. "O Discurso do Método de Montaigne”. p. XXIV.

7. ANDRADE, Mário de. A Lição do Amigo: cartas de Mário de Andrade a Carlos Drummond de Andrade. p. 26.

8. ANDRADE, Mário de. Vida Literária. p. 14 (fonte de todas as citações do parágrafo).

9. ADORNO, Theodor W. "O Ensaio como Forma”.p. 25 (fonte de todas as citações do parágrafo)

10. ADORNO, Theodor W. "O Ensaio como Forma". p. 36.

11. MONTAIGNE, Michel de. Os ensaios [vol. I]. p. 342.

12. MONTAIGNE, Michel de. Os ensaios [vol. I]. p. 343.

13. MONTAIGNE, Michel de. Os ensaios [vol. I]. p. 346.

14. MONTAIGNE, Michel de. Os ensaios [vol. I]. p. 346.

15. ARRIGUCCI JR. Davi. "Movimentos de um leitor (Ensaios e imaginação crítica em Antonio Candido)”.p. 237.

16. ANDRADE, Mário de. Vida Literária. p. 122.

17. Texto original: “[...] Ora qual não me foi o meu assombro logo em seguida, ao reparar que esse poema que me fizera tanto pensar e vibrar, não era poema nem nada, era apenas a seriação dos títulos das poesias que iam seguir, a que o poeta não ajuntara nem a indicação de "Índice" nem numeração das páginas [...]” In: ANDRADE, Mário de. Vida Literária. p. 122.

18. Texto original: "[...] Como arte, ele [Machado] foi o maior artesão que já tivemos. E esta é a sua formidável vitória e sua maior lição. Ele vence, ele domina tudo, pelo artista incomparável que soube ser. Tomando a sério a sua arte, Machado de Assis se aplicou em conhecê-la com uma técnica maravilhosa. É impossivel se imaginar maior domínio do métier. Fonte de exemplo, fonte de experiência, treino indispensável, dador fecundo de saúde técnica.” In: ANDRADE, Mário de. Vida Literária. p. 58.

19. AUERBACH, Eric. “O escritor Montaigne”. p. 151.

20. AUERBACH, Eric. “O escritor Montaigne”. p. 149.

\section{RESUMOS}

Este artigo tem como objetivo levantar algumas hipóteses sobre um possível diálogo entre as concepções de escrita ensaística do modernista brasileiro, Mário de Andrade, e os comentários concernentes à forma do iniciador do gênero ensaístico, Montaigne. Apesar da distância entre o 
universo dos dois escritores, há semelhanças na concepção do gênero ensaio, que se relacionam à ideia de que a escrita ensaística partiria da intuição e, por isso, incluiria, além de especulações críticas, um desdobramento do eu. Assim, tanto no autor de Ensaios, como no de Macunaíma, a escrita ensaística, além das múltiplas hipóteses levantadas no interior de cada texto, reflete as concepções morais próprias às concepções particulares e às máscaras assumidas pelo escritor em cada contexto.

Cet article a pour but d'établir quelques hypothèses sur un possible rapport entre les différentes conceptions d'essai présentes chez l'écrivain brésilien Mário de Andrade et les commentaires sur la forme qu'on peut rencontrer chez Montaigne, l'inventeur de ce genre. Malgré le grand écart de temps entre les deux écrivains, il est possible de repérer quelques points en commun dans leurs œuvres. Ils se trouvent dans la façon dont les deux écrivains conçoivent le genre, en tenant comme principe la notion d'intuition. Ainsi, l'écriture contiendrait non seulement des spéculations critiques, mais un dédoublement du moi. En conséquence, chez l'auteur des Essais aussi bien que chez Mário de Andrade, au-delà de multiples hypothèses soulevées à l'intérieur de chaque texte concernant l'idée d'essai, l'écriture révélerait quelques conceptions morales en syntonie avec leurs conceptions particulières et les masques portés par chacun, à chaque moment.

\section{ÍNDICE}

Palavras-chave: literatura comparada, modernismo no Brasil, ensaio, Mário de Andrade, Michel de Montaigne

Mots-clés: littérature comparée, modernisme au Brésil, essai, Mário de Andrade, Michel de Montaigne

\section{AUTOR}

\section{RICARDO GAIOTTO DE MORAES}

Doutorando em Teoria e História Literária - IEL/Unicamp/Fapesp

rgaiotto[at]gmail.com 